ORIGINAL ARTICLE

\title{
Type of acute hamstring strain affects flexibility, strength, and time to return to pre-injury level
}

\author{
C Askling, T Saartok, A Thorstensson
}

Br J Sports Med 2006;40:40-44. doi: 10.1136/bjsm.2005.018879

See end of article for authors' affiliations

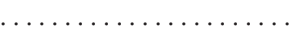

Correspondence to: Mr Askling, Karolinska Institutet, Stockholm Sweden; carl.askling@ihs. se

Accepted 20 June 2005
Objectives: To investigate possible links between aetiology of acute, first time hamstring strains in sprinters and dancers and recovery of flexibility, strength, and function as well as time to return to pre-injury level. Methods: Eighteen elite sprinters and 15 professional dancers with a clinically diagnosed hamstring strain were included. They were clinically examined and tested two, 10, 21, and 42 days after the acute injury. Range of motion in hip flexion and isometric strength in knee flexion were measured. Self estimated and actual time to return to pre-injury level were recorded. Hamstring reinjuries were recorded during a two year follow up period.

Results: All the sprinters sustained their injuries during high speed sprinting, whereas all the dancers were injured while performing slow stretching type exercises. The initial loss of flexibility and strength was greater in sprinters than in dancers $(p<0.05)$. At 42 days after injury, both groups could perform more than $90 \%$ of the test values of the uninjured leg. However, the actual times to return to pre-injury level of performance were significantly longer (median 16 weeks (range 6-50) for the sprinters and 50 weeks (range 30-76) for the dancers). Three reinjuries were noted, all in sprinters.

Conclusion: There appears to be a link between the aetiologies of the two types of acute hamstring strain in sprinters and dancers and the time to return to pre-injury level. Initially, sprinters have more severe functional deficits but recover more quickly.
A cute hamstring strains are common injuries in sport. ${ }^{1}$ They are often serious, causing long rehabilitation times and a distinct proneness to reinjury. ${ }^{23}$ Recent evidence suggests that hamstring strains can be of at least two types, one occurring during high speed running, as in football ${ }^{4}$ and athletics, ${ }^{5}$ and the other occurring during stretching movements carried out to an extreme range of motion. ${ }^{6}$ It is not known whether these two types of hamstring strain affect loss of function, flexibility, and strength differently. The latter two variables are critical for performance and are often used for establishing criteria for return to full activity. ${ }^{78}$ Results indicating that type of injury may affect time to return to pre-injury level were presented in a case study, ${ }^{9}$ where a dancer with a "stretching type" of hamstring injury had a much longer recovery time than a sprinter with a "high-speed running type" of injury. Interestingly, a magnetic resonance imaging (MRI) examination showed different injury localisation as well as different tissues involved in the two cases. ${ }^{9}$

The purpose of this study was to conduct a systematic follow up after acute first time hamstring strains in sprinters and dancers, including recovery of flexibility, strength, and function, as well as time to return to pre-injury level.

\section{METHODS \\ Subjects}

Thirty three subjects were included: 18 sprinters (eight female and 10 male, age range $15-28$ years, body mass $53-$ $84 \mathrm{~kg}$, height $1.59-1.82 \mathrm{~m}$ ) and 15 dancers (14 female and one male, $16-24$ years, $48-68 \mathrm{~kg}, 1.58-1.80 \mathrm{~m}$ ). The sprinters competed at national or international level, and the dancers were either in education or employed, performing both modern and classic dance. Approval for the study was granted from the ethics committee of the Karolinska Institutet.

\section{Recruitment procedure}

The subjects were recruited in response to information given to all major track and field clubs in Sweden by the Swedish Athletic Association, and to dance schools and employers of dancers in the Stockholm area by the Swedish Society of Dance Medicine. All potential subjects who suffered an injury to the back of the thigh were asked to contact the study leader (CA) by phone on the day of injury. They were then informed about the background of the study and invited to participate on a completely voluntary basis.

\section{Inclusion/exclusion criteria}

To be included the subjects had to have a history of first time acute sudden pain from the posterior thigh when training, competing, or performing. The first clinical examination (two days after the injury) had to reveal distinct pain when the hamstring muscle was palpated, local pain when a passive straight leg raise test was performed, and increased pain when an isometric hamstring contraction was added during that test. Exclusion criteria were extrinsic trauma to the posterior thigh (contusions), ongoing or chronic low back problems, pregnancy, and confirmed or even suspected earlier hamstring strains in the same leg. In all, 54 subjects (30 dancers and 24 sprinters) had to be excluded, all because of an earlier hamstring injury. The recruitment took five years. All subjects included in the study subsequently had their clinically diagnosed injury confirmed by MRI.

\section{Clinical examination}

The subjects were examined on four occasions (I-IV), two, 10, 21, and 42 days after the acute injury. On the first occasion, patients were interviewed about the injury situation-that is, the movements or exercises during which the

Abbreviations: $M R I$, magnetic resonance imaging; $R O M$, range of motion 


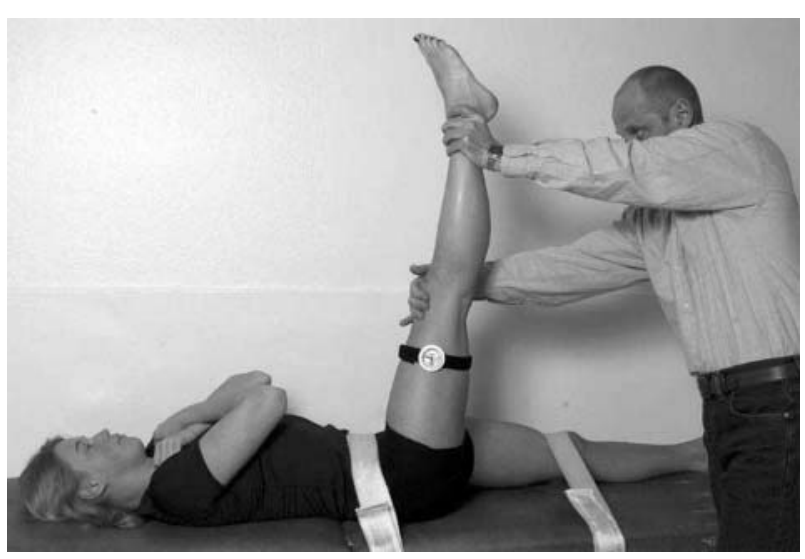

Figure 1 The straight leg raise test. The people in the picture have given their written consent for publication.

injury had occurred. The presence of pre-injury symptoms in the posterior thigh was recorded. The functional observations encompassed ability to walk without crutches and ability to walk on flat ground without pain. Palpation of the posterior thigh was performed with the subjects prone and the knee extended. The point at which the subject noted the greatest pain on palpation was marked, and the distance to the tuber ossis ischii measured. All clinical examinations, functional observations, and interviews were performed by the study leader (CA).

\section{Tests}

All subjects were tested for flexibility and strength at the same time of day on all four test occasions. The uninjured leg was always tested before the injured leg, and flexibility before strength. The tests were selected to minimise the risks of aggravating the acute injury; therefore we chose an isometric as opposed to a dynamic strength test and a flexibility test in which the subject determined the range of movement according to pain experienced (see below).

\section{Hip flexibility}

The hip flexion test (fig 1) combined a passive unilateral straight leg raise test with pain estimation according to the Borg CR-10 scale. ${ }^{10}$ The subjects were placed supine with the pelvis and contralateral leg fixed with straps. A standard flexometer (Myrin, Follo A/S, Norway, sensitivity $2^{\circ}$ ) was placed $10 \mathrm{~cm}$ proximal to the base of the patella. The foot was plantar flexed and the investigator slowly (about $30 \%$ ) raised the leg with the knee straight until the subject estimated a 3 ("moderate pain") on the Borg CR-10 scale $(0=$ no pain and $10=$ maximal pain). The hip flexion angle at this point was recorded, and the greatest angle of three repetitions was

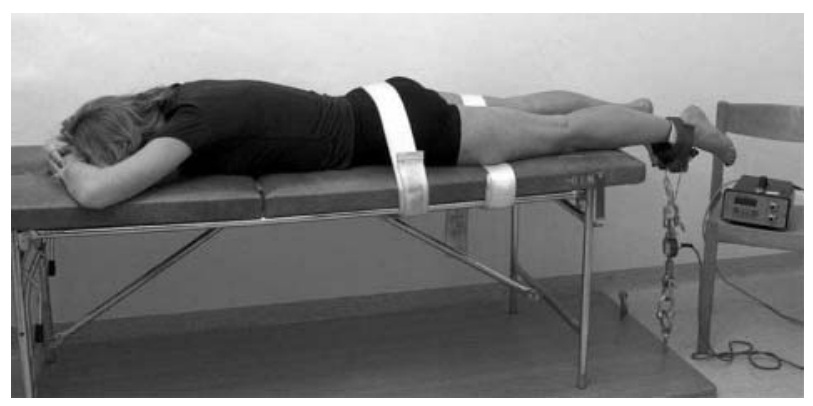

Figure 2 The isometric knee flexion strength test. The person in the picture has given her written consent for publication. taken as the test result. No warm up preceded the flexibility measurements.

\section{Knee flexion strength}

Isometric knee flexion strength was measured with the subject in a prone position and the pelvis and the contralateral leg fixed (fig 2). A dynamometer (Bofors KRG-4 T10; Nobel Elektronik, Karlskoga, Sweden; range 0$4 \mathrm{kN}$ ) was placed at the ankle, perpendicular to the lower leg. The foot was in plantar flexion and the knee in an extended position. Three maximal voluntary isometric knee flexion contractions were performed with gradually increasing effort. Each contraction lasted three seconds, with 30 seconds of rest between. The highest force value was recorded and converted into torque (strength) by multiplying by the lever arm-that is, the distance from the point of force application to the lateral articular cleft of the knee.

\section{Follow up}

On the first test occasion (two days) each subject's self estimated time to return to pre-injury level was recorded. All subjects received the same standardised three part progressive rehabilitation programme. The three parts were in clinical examinations I, II, and III. After the last examination, six weeks after the injury, continued rehabilitation was administered by the respective athlete's doctor and physiotherapist. The subjects were asked to note the week when they could train, compete, or perform at their pre-injury level-that is, competing at similar best times for the sprinters and being able to train and perform without restriction for the dancers. The athletes were asked to contact the study leader immediately by phone if reinjury occurred. Follow up phone calls were carried out by the study leader at three, 12, and 24 months after the occurrence of the initial injury, and then any symptoms or problems from the previously injured hamstring muscle were noted. The full follow up period ( 24 months) was not completed for three of the sprinters $(19,21$, and 22 months) and three of the dancers (five, 17, and 19 months).

\section{Statistical analysis}

Shapiro-Wilk's W test was applied to examine normality in the distribution of data. To estimate the test-retest reliability of the hip flexibility test and the isometric knee flexion strength test, the values for the uninjured leg on test occasions I and II, eight days apart, were used to calculate the intraclass correlation ( $\alpha$ value) of the measurements with $95 \%$ confidence interval (CI) ${ }^{11}$ Values for the injured leg were expressed as a percentage of the uninjured leg for comparisons within and between groups. Analysis of variance with post hoc Tukey test and Student's $t$ test were used to detect significant differences. Spearman rank order correlation was calculated between subjects' test results and time to return to pre-injury level. Fisher's exact test was used to compare the groups with respect to functional observations. The significance level was set at $\mathrm{p}<0.05$.

\section{RESULTS}

\section{Clinical examination}

All sprinters reported that they had suffered their injuries during competition sprinting when the speed was maximal or close to maximal. In contrast, all dancers obtained their injuries in slow stretching types of exercise: 11 occurred in the sagittal split and four in the side split. In the dancers, five injuries occurred while warming up, seven while cooling down, and three during performance or training. All 18 sprinters were forced to stop their sprinting immediately when the injury occurred, and 11 actually fell. Only six of the 15 dancers had to interrupt their activity. None of the 
Table 1 Range of motion (degrees) for the hip flexibility test in the injured and uninjured leg in sprinters $(n=18)$ and dancers $(n=15)$ in the four tests (I-IV)

\begin{tabular}{llllll}
\hline & \multicolumn{2}{l}{ Sprinters } & & \multicolumn{2}{l}{ Dancers } \\
\cline { 2 - 3 } Test & Injured & Uninjured & & Injured & Uninjured \\
\hline I & $54(16)^{*}$ & $88(14)$ & $95(14)^{*}$ & $119(19)$ \\
II & $71(14)^{*}$ & $89(15)$ & $104(14)^{*}$ & $119(17)$ \\
III & $81(14)^{*}$ & $90(15)$ & $106(14)^{*}$ & $118(18)$ \\
IV & $84(15)^{*}$ & $90(16)$ & $108(19)^{*}$ & $118(19)$ \\
\hline \multicolumn{2}{l}{ Values are mean (SD). } \\
*Significantly different from the uninjured leg (p<0.05).
\end{tabular}

sprinters and only two of the dancers reported symptoms before the injury-for example, muscle pain. On the first test occasion, 15 sprinters were using crutches, but none of the dancers $(p<0.05)$. None of the sprinters could walk on flat ground without pain, compared with seven of the dancers $(p<0.05)$. At the fourth test all sprinters could jog without pain, but three of the dancers still had problems. The sprinters noted their greatest pain on palpation at a more distal location than the dancers (mean (SD) distance from tuber ossis ischii $12(6) \mathrm{cm}$ (range 5-24) $v 1(0.7) \mathrm{cm}$ (range $1-3)$; $\mathrm{p}<0.05)$.

\section{Hip flexibility}

The intraclass correlation between tests I and II of hip flexibility of the uninjured leg was 0.98 (95\% CI 0.95 to 0.99 ). The results showed a large decrease in range of motion (ROM) of the injured leg in both groups at the first test (table 1, fig 3). Over the subsequent six weeks, the subjects gradually recovered the ROM of their injured leg, but this leg was still significantly less flexible in both groups at the last test (table 1, fig 3). The difference in ROM between the two legs was significantly larger for the sprinters than for the dancers at the first test (fig 3). The ROM of the uninjured leg did not change over time (table 1).

\section{Knee flexion strength}

The ICC between tests I and II of knee flexor strength of the uninjured leg was 0.98 (95\% CI 0.96 to 0.99 ). Both groups showed significantly less strength in the injured leg at the first test (table 2, fig 4). At the following tests, this difference gradually decreased. At the last two tests, there were no significant differences in strength between the legs in the dancers, whereas significant differences remained for the sprinters (table 2, fig 4). The decrease in strength of the injured leg at the first test was significantly larger for the sprinters than for the dancers (fig 4). The strength of the

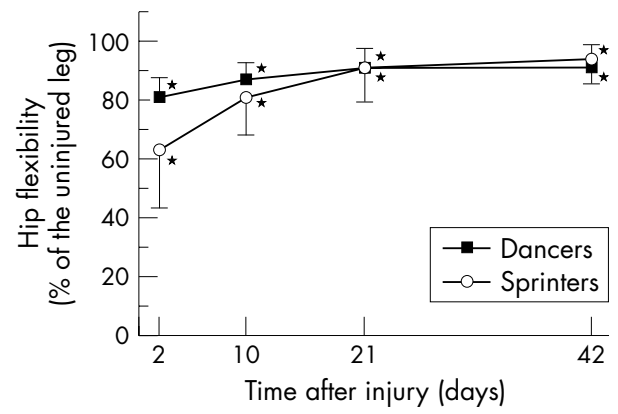

Figure 3 Mean values ( \pm ISD) of hip flexibility (range of motion) of the injured leg expressed as a percentage of the uninjured leg in the sprinters $(n=18)$ and dancers $(n=15)$ on the four test occasions (for absolute values see table 1). *Significantly less flexibility in the injured than the uninjured leg.

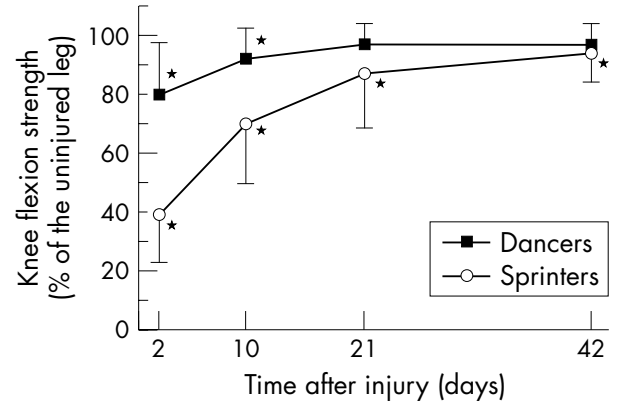

Figure 4 Mean values $( \pm 1 S D)$ of knee flexion strength in the injured leg expressed as a percentage of the uninjured leg in the sprinters ( $\mathrm{n}=$ 18 ) and dancers $(n=15)$ in the four tests (for absolute values see table 2). *Significantly less strength in the injured than the uninjured leg.

uninjured leg did not change over the observation period (table 2).

\section{Follow up}

The median (range) self estimated time to return to preinjury level was significantly longer for the sprinters (four weeks, range 2-12) than for the dancers (one week, range 12 ). The actual time back was significantly longer than self estimated for both groups, median values being 16 weeks (range 6-50) for the sprinters and 50 weeks (range 30-76) for the dancers. The actual time back was significantly longer for the dancers than for the sprinters (fig 5). At the last test, six weeks after the injury, none of the dancers, and only two of the sprinters, were able to participate fully in their respective sport according to their own judgment. These two sprinters had both regained $96 \%$ of their strength and $87 \%$ and $95 \%$ of their ROM. In neither sprinters nor dancers were there any correlations between hip ROM or strength at the first test and the time to return to pre-injury level. One dancer decided to end her dancing career 17 months after the initial injury because of chronic symptoms from her hamstring strain. During the two year follow up, three sprinters ( $17 \%)$ had reinjuries of their hamstrings (eight, nine, and 20 months after the first injury), and two of them had to finish their athletic careers. None of the subjects had any other serious injuries during the follow up period.

\section{DISCUSSION}

This study shows the existence of two types of acute hamstring strain, distinguished by different aetiologies, in sprinters and dancers. Further, the results indicate that there may be a link between type of hamstring strain and the acute loss of function and performance in strength and flexibility tests, as well as in the time to return to pre-injury level. The hamstring strains occurring in sprinters during maximal speed running caused a more striking acute decline in function, but had a faster recovery time than those occurring 
Table 2 Strength (N.m) in the knee flexor strength test in the injured and uninjured leg in sprinters $(n=18)$ and dancers $(n=15)$ in the four tests (I-IV)

\begin{tabular}{|c|c|c|c|c|}
\hline \multirow[b]{2}{*}{ Test } & \multicolumn{2}{|l|}{ Sprinters } & \multicolumn{2}{|l|}{ Dancers } \\
\hline & Injured & Uninjured & Injured & Uninjured \\
\hline 1 & $36(15)^{*}$ & $95(18)$ & $56(19)^{*}$ & 69 (17) \\
\hline ॥ & $66(15)^{*}$ & $98(20)$ & $66(18)^{*}$ & $72(17)$ \\
\hline III & $80(25)^{*}$ & $93(26)$ & 70 (17) & 73 (17) \\
\hline IV & $93(19)^{*}$ & $102(20)$ & 70 (19) & 71 (18) \\
\hline
\end{tabular}

in extreme positions during stretching exercises in dancers. Interestingly, there were no correlations between time to return to pre-injury level and the magnitude of the acute loss or short term recovery of hip flexibility or knee flexion strength.

The occurrence of hamstring strain injuries in high speed running has been documented previously, ${ }^{5}{ }^{12}$ but the exact instant of injury during the stride cycle is still based on speculation and indirect evidence. ${ }^{13}$ The injury seems to be related to the magnitude of force, rate of force development, and/or length change rather than extreme joint positions. ${ }^{13}$ The present results and our recent observations ${ }^{6}{ }^{9}$ show that acute hamstring strains can occur even in slow, apparently well controlled, stretching exercises performed to the limit of flexibility - that is, to extreme lengths of at least some of the muscle-tendon units involved.

There was a clear initial decrement in passive flexibility and maximal voluntary strength in both groups. This decrease can be attributed to several factors-for example, the extent of damaged tissue-and related physiological and psychological phenomena-for example, pain and fear of activating the injured muscle. Interestingly, the acute detrimental effects of the injury on performance were clearly larger in the sprinters than in the dancers. Speculations on the reasons for this include differences in the tissues involved. ${ }^{9}$

The recovery of function, flexibility, and strength was remarkably fast, particularly for the more severe initial impairments in the sprinters. Already at 10 days after the injury, none of the subjects in any group needed crutches during walking, and flexibility and strength for the injured leg were back to 70-92\% of the uninjured leg. After the initial six week period, both groups could perform, on average, more than $90 \%$ of the uninjured side in the flexibility and strength tests. Still, all of the subjects stated that apprehension and fear from overexerting their injured muscles prohibited them from exposing themselves to pre-injury levels of exertion.

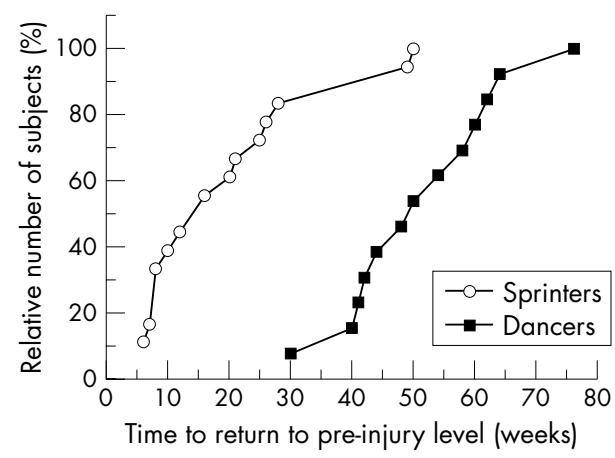

Figure 5 Relative number of subjects in each group plotted against the corresponding time, in weeks, to return to pre-injury level of performance ( $\mathrm{n}=18$ for the sprinters and $\mathrm{n}=13$ for the dancers).

\section{What this study adds}

- This study illustrates two types of acute hamstring strain, distinguished by different aetiologies in sprinters and dancers, the latter occurring during stretching exercises

- Clear differences between the groups in acute loss of function, flexibility, and strength, as well as in time to return to pre-injury level are shown

\section{What is already known on this topic}

- Hamstring muscle strains are common in both individual and team sports with high demands on speed and power

- They often cause severe functional impairments and extensive time periods away from training and competition, and the recurrence rate is high

These results highlight the question of objective criteria based on tests versus the subjective feeling of aptitude and "security". It is evident that these two criteria do not correlate well here. A 90-95\% level of test performance, as is often recommended as a return criterion in textbooks, did not make the athletes confident that they could return safely to full competition and performance.

The time until the subjects considered themselves ready to return to full activity was long. Also, the time was clearly longer for the dancers than for the sprinters (median 50 weeks $v 16$ weeks). A longer time was also reported for a dancer ( 52 weeks) than for a sprinter (12 weeks) in the case study by Askling et al. ${ }^{9}$ In that study, differences in damaged tissues were also detected with MRI, the sprinter's strain involving primarily muscular tissue, and the dancer's strain more proximal tendinous tissue. In line with these findings was the significantly more proximal location of the palpation pain in the dancers observed here. A possible connection between injury location and recovery time is under investigation.

It is realised that, so far, we are basing our coupling between the two injury types and their consequences for function and recovery on results from two groups differing in type of activity, dominant sex, and possibly also goals and objectives. Studies need to be expanded to make more general conclusions possible. Importantly, however, in our continued collection of cases with hamstring strains, we have 
come across several athletes in other sports, who fall into either of the two categories of injury, including sprinters who have suffered "stretching-type" hamstring strains with similar symptoms and outcomes to the dancers. In team sports it has been reported that players recover, on average, far quicker than either of the two current groups, ${ }^{14}{ }^{15}$ but potentially they may be competing again without being fully recovered to their pre-injury level, whereas dancers and sprinters probably need much closer to full function.

Previous injury is one of the most prominent predisposing factors for reinjury to the hamstrings. In studies on Australian football, it has been shown that reinjuries are more common for hamstring strains than for other types of injury. ${ }^{3}$ In our study the reinjury rate was $17 \%$ (sprinters). In an extensive study on hamstring injuries sustained in English professional football over two competitive seasons, Woods et $a l^{4}$ reported a reinjury rate of $12 \%$. In this context, it is worth noticing that, of the hamstring injuries occurring in the footballers, most were attributed to running, but, interestingly enough, the second most common "mechanism" reported was stretching. ${ }^{4}$

In summary, the acute hamstring strains in sprinters and dancers had different aetiologies. The two groups also clearly varied with respect to loss and recovery of flexibility, strength, and function as well as time to return to pre-injury level of performance. This may be related to differences in injury mechanisms and tissues involved. The possible influence of other factors-for example, sport specific demands, sex, and personality-needs further investigation. The two types of hamstring strain may require specifically adapted training regimens for prevention and optimal rehabilitation.

\section{ACKNOWLEDGEMENTS}

We thank the Swedish Centre for Sport Research for financial support.
Authors' affiliations

C Askling, T Saartok, A Thorstensson, Karolinska Institutet, Stockholm, Sweden

Competing interests: none declared

Written informed consent for publication has been obtained from the persons appearing in figs 1 and 2 .

\section{REFERENCES}

1 Koulouris G, Connell D. Evaluation of the hamstring muscle complex following acute injury. Skeletal Radiol 2003:32:582-9.

2 Croisier JL. Factors associated with recurrent hamstring injuries. Sports Med 2004;34:681-95.

3 Orchard J, Best TM. The management of muscle strain injuries: an early return versus the risk of recurrence. Clin J Sport Med 2002;12:3-5.

4 Woods C, Hawkins RD, Maltby S, et al. The Football Association Medical Research Programme: an audit of injuries in professional football - analysis of hamstring injuries. Br J Sports Med 2004;38:36-41.

5 Yamamoto T. Relationship between hamstring strains and leg muscle strength. J Sports Med Phys Fitness 1993;33:194-9.

6 Askling C, Lund H. Saartok T, et al. Self-reported hamstring injuries in studentdancers. Scand J Med Sci Sports 2002;12:230-5.

7 Witurouw E, Danneels L, Asselman P, et al. Muscle flexibility as a risk factor for developing muscle injuries in male professional soccer players. Am J Sports Med 2003;31:41-6.

8 Croisier JL, Forthomme B, Namurois MH, et al. Hamstring muscle strain recurrence and strength performance disorders. Am J Sports Med 2002;30: 199-203.

9 Askling C, Tengvar M, Saartok T, et al. Sports related hamstring strains: two cases with different etiologies and injury sites. Scand J Med Sci Sports 2000;10:304-7.

10 Borg G, Holmgren A, Lindblad I. Quantitative evaluation of chest pain. Acta Med Scand 1981;644(suppl.):43-5.

11 Muller R, Buttner P. A critical discussion of intraclass correlation coefficients. Stat Med 1994; 13:2465-76.

12 De Smet A, Best T. MR imaging of the distribution and location of acute hamstring injuries in athletes. AJR Am J Roentgenol 2000;174:393-9.

13 Thelen DG, Chumanov ES, Hoerth DM, et al. Hamstring muscle kinematics during treadmill sprinting. Med Sci Sports Exerc 2005:37:108-14.

14 Connell DA, Schneider-Kolsky ME, Hoving JL, et al. Longitudinal study comparing sonographic and MRI assessments of acute and healing hamstring injuries. AJR Am J Roentgenol 2004;183:975-84.

15 Slavotinek JP, Verrall GM, Fon GT. Hamstring injury in athletes: using MR imaging measurements to compare extent of muscle injury with amount of time lost from competition. AJR Am J Roentgenol 2002;179:1621-8. 